\title{
Impact of hand forces and start/stop frequency on physiological responses to three forms of pushing and pulling: A South African perspective
}

\author{
Todd $\mathrm{AI}^{\mathrm{a}, *}$ \\ ${ }^{a}$ Department of Human Kinetics and Ergonomics, PO Box 94, Rhodes University, Grahamstown, South Africa, \\ 6140
}

\begin{abstract}
There has been limited attention given to the physiological demands of pushing and pulling, especially in industrially developing countries such as South Africa. Two key factors affecting the physiological demands of these tasks are the hand forces exerted and the start/stop frequency. The purpose of the current study was therefore to investigate the physiological responses to pushing and pulling at various loads and start/stop frequencies. 36 male subjects participated in the study and were required to complete a total of 18 conditions (three techniques: pushing, two- and one-handed pulling; three loads: 200, 350 and $500 \mathrm{~kg}$; and two frequencies: 2 and 4 stops per minute). During each condition the heart rate, oxygen uptake and energy expenditure were measured. Pushing was found to elicit significantly lower responses for all three dependent variables than either form of pulling. The start/stop frequency was also found to have a significant impact on subject responses. The findings of this study indicate that the technique adopted to maneuver loads is critical in determining the physical demands placed on the human operator. Furthermore increasing the frequency of start/stops plays an important role, thus the forces exerted during these two phases are important from a physiological perspective.
\end{abstract}

Keywords: Pushing, pulling, physiology, frequency, South Africa

\section{Introduction}

Lifting, carrying and lowering have historically been the predominant forms of manual materials handling (MMH) and consequently have been the focus of much research. This research has highlighted the high risks associated with these tasks for the development of musculoskeletal disorders [1-3]. Consequently many lifting tasks have been replaced with the introduction of manual handling devices (MHDs) including carts, trolleys and hoists [4-5]. However the result is that the movement of MHDs is usually characterized by some form of pushing and pulling. Consequently nearly half of all MMH tasks now involve pushing and pulling, increasing the need to better understand how these altered task demands impact on the human operator [6-7].

The primary focus of research into pushing and pulling has been on biomechanical factors including the posture adopted, hand forces and lower back biomechanics. There has however been limited attention given to the physiological demands of these tasks with studies on the physiological costs being scarce [6]. Furthermore, the studies that have been conducted have either been performed in industrially developed regions [8] or over three decades ago in developing countries such as India [9]. The applicability of this research to the South African context, which is characterised by the cycle of disease [10], is questionable. Two key factors affecting the physiological demands of pushing and pulling are the hand

\footnotetext{
*Corresponding author. Name: Andrew Todd; Address: HKE Department, Rhodes University, Grahamstown, South Africa, 6140;
} Tel: +2746038469; E-mail: a.todd@ru.ac.za. 
forces exerted and the start/stop frequency. Therefore the purpose of the current study was to investigate the physiological responses of South African subjects to pushing and pulling at varying loads (to manipulate hand forces) and start/stop frequencies, in order to establish the optimal technique, hand forces and frequencies to be used within an industrially developing context.

\section{Methods}

\subsection{Study Design}

The primary independent variable was the technique adopted, with the three most common forms of pushing and pulling forming the basis for experimentation: forward bilateral pushing, forward unilateral and backward bilateral pulling. Furthermore these three techniques were assessed at three different loads similar to those used in other studies $[6,8]$ of 200,350 and $500 \mathrm{~kg}$ and two frequencies of two and four start/stops per minute. Thus, subjects were required to complete a total of 18 experimental conditions, which were presented in random order to ensure that fatigue effects did not affect the responses.

Participants in the study maneuvered a hydraulic pallet jack loaded with the appropriate weight (mass of the pallet jack (78kg) included in the calculation) along a friction controlled walkway. A total distance of $20 \mathrm{~m}$ was covered in one direction, with one and two start/stops for the two and four start/stop frequencies respectively. A research assistant then turned the pallet jack around and the subjects were required to resume pushing or pulling. Subjects were required to keep performing the required condition for six minutes at a walking speed of $1 \mathrm{~m} \cdot \mathrm{s}^{-1}$. A time frame of six minutes was selected for the current study as the subjects should have reached steady state by this time. Furthermore subjects completed three experimental conditions per session, thus were required to attend a total of six experimental sessions.

Physiological responses (heart rate, oxygen uptake and energy expenditure) were collected using the Cosmed ${ }^{\circledR} \mathrm{K} 4 \mathrm{~b}^{2}$ ergospirometer for all 18 experimental conditions. Data from the $3^{\text {rd }}$ and $6^{\text {th }}$ minute were then extracted for further statistical analysis.

\subsection{Participants}

36 male subjects participated in the study and were drawn from the Rhodes University student population.
All subjects were given extensive habituation to all experimental procedures and particularly to the pushing and pulling of the pallet jack. The subjects had a mean age of $22( \pm 2)$ years, with a mass of $76( \pm 9.02)$ $\mathrm{kg}$ and stature of $1781( \pm 54) \mathrm{mm}$.

\subsection{Procedures}

All subjects were required to attend one ninety minute familiarization session and six, one hour, experimental sessions. In the familiarization session subjects were informed both in writing and verbally of the requirements of the study. Once all questions had been answered the subjects were required to sign informed consent and demographic and anthropometric data were collected. In the experimental sessions subjects were fitted with the appropriate equipment including a Polar heart rate monitor and the face mask for gas analysis. Subjects were then required to perform each condition for a total of six minutes, which is the equivalent of 12 and 24 start/stops for the low and high start/stop frequencies respectively. After the completion of one condition subjects were provided with a rest period to ensure that physiological responses had returned to resting values and to avoid fatigue effects.

\subsection{Statistical Procedures}

For statistics, descriptive statistics were calculated, followed by multivariate analysis of variance (ANOVA) to assess significant effects. Where differences were found further analysis was done using the Tukey post-hoc analysis to determine the position of the significant differences.

\section{Results}

\subsection{Impact of hand forces}

Hand forces in the current study were manipulated by changing the load placed onto the pallet jack. As with previous studies [4, 8] a linear relationship between the load moved and hand forces was found. The responses for the current study indicate that the load moved (i.e. the hand forces exerted) played an integral role in determining the physiological demands of pushing and pulling.

Figure 1 demonstrates the linear relationship between oxygen uptake and hand forces for all three of 
the techniques adopted in the current study. An increase in load was associated with an increase in oxygen consumption, with significant differences being evident for all three loads. For the lightest load the oxygen consumption ranged between 12.80 and $15.27 \mathrm{ml} \cdot \mathrm{kg}^{-1} \cdot \mathrm{min}^{-1}$, with an average consumption of $13.82 \mathrm{ml} \cdot \mathrm{kg}^{-1} \cdot \mathrm{min}^{-1}$ across the six experimental conditions for this load. This figure increased to 17.66 and $22.48 \mathrm{ml} \cdot \mathrm{kg}^{-1} \cdot \mathrm{min}^{-1}$ as the load increased to 350 and $500 \mathrm{~kg}$ respectively, representing approximately a $39 \%$ increase. The figure further demonstrates that there was a significant increase in the oxygen demand as the load increased from 200 to $500 \mathrm{~kg}$ regardless of the technique adopted.
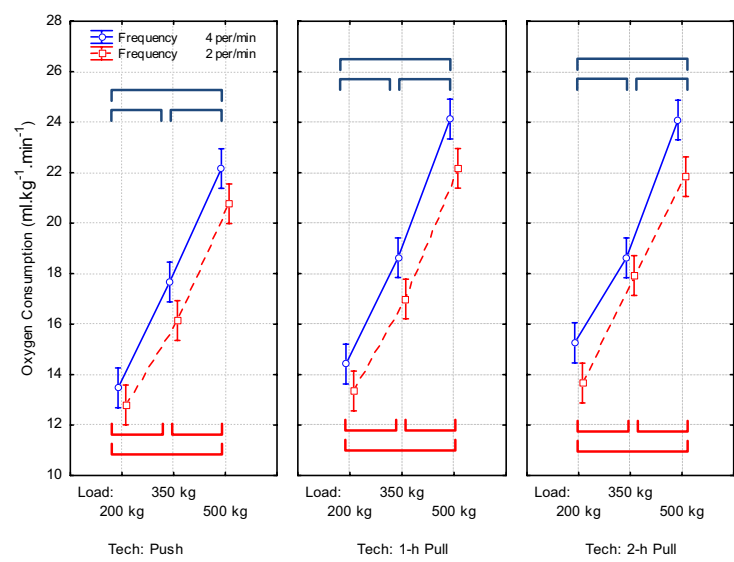

Figure 1: Impact of hand forces on oxygen consumption responses (Brackets denote a significant difference $(\mathrm{p}<0.05)$ between loads; Vertical bars denote 0.95 confidence intervals)

Heart rate when moving $500 \mathrm{~kg}$ was significantly higher (an average of $125 \mathrm{bt} \cdot \mathrm{min}^{-1}$ ) than for either of the other two loads. Moving $350 \mathrm{~kg}$ resulted in an average heart rate of 109 bt.min ${ }^{-1}$ which was significantly higher than the $97 \mathrm{bt}_{\mathrm{min}}{ }^{-1}$ found for $200 \mathrm{~kg}$ (see Table I). Increments in load from 200 to 350 and $500 \mathrm{~kg}$ resulted in statistically significant increases in the associated energy cost which increased from 5.14 kcal.min ${ }^{-1}$ at $200 \mathrm{~kg}$ to 6.59 and $8.41 \mathrm{kcal} . \mathrm{min}^{-1}$ at the two heavier loads respectively. This is an approximate $28 \%$ increase for both increments (i.e. for 200 to 350 and 350 to $500 \mathrm{~kg}$ ), for a total increase of 3.27 kcal.min ${ }^{-1}$ (approximately 64\%).
Table I

Heart rate and energy cost for the three experimental loads (meaned for the six experimental conditions at each load)

\begin{tabular}{|l|c|c|c|}
\hline & $200 \mathrm{~kg}$ & $350 \mathrm{~kg}$ & $500 \mathrm{~kg}$ \\
\hline $\begin{array}{l}\text { Heart Rate } \\
(\text { bt.min }\end{array}$ & 97 & 109 & 125 \\
\hline $\begin{array}{l}\text { Energy Cost } \\
(\text { kcal.min }\end{array}$ & 5.14 & 6.59 & 8.41 \\
\hline
\end{tabular}

\subsection{Impact of Technique}

When considering the impact of technique (results for load and distance aggregated) it is evident that heart rate responses were statistically $(\mathrm{p}<0.05)$ lower for pushing (108 bt.min $\left.{ }^{-1}\right)$ than the other two techniques (111 and $113 \mathrm{bt} \cdot \mathrm{min}^{-1}$ for one- and twohanded pulling respectively). There was no statistical difference between the two techniques of pulling. Results however indicate that when technique was matched for frequency and load there were no significant differences found, with the greatest difference between techniques of only $7 \mathrm{bt} \cdot \mathrm{min}^{-1}$ for the high frequency, high load conditions and medium load, low frequency tasks. It would therefore appear that although overall pushing resulted in the lowest heart rate responses, the differences between matched conditions were small.

Table II

Impact of technique on physiological responses (Brackets indicate significant differences between techniques)

\begin{tabular}{|l|c|c|c|}
\hline & Pushing & $\begin{array}{l}\text { 1-handed } \\
\text { pulling }\end{array}$ & $\begin{array}{l}\text { 2-handed } \\
\text { pulling }\end{array}$ \\
\hline $\begin{array}{l}\text { Heart Rate } \\
(\text { bt.min }\end{array}$ & 108 & 111 & 113 \\
\hline $\begin{array}{l}\text { Oxygen Uptake } \\
\left(\mathrm{ml.kg}^{-1} \mathrm{~min}^{-1}\right)\end{array}$ & 17.12 & 18.28 & 18.58 \\
\hline $\begin{array}{l}\text { Energy Cost } \\
\left(\mathrm{kcal.min}^{-1}\right)\end{array}$ & 6.35 & 6.83 & 6.97 \\
\hline & \llcorner & & \\
\hline
\end{tabular}

As with heart rate responses, technique played a role in determining the oxygen consumption responses to the 18 experimental conditions. Overall oxygen uptake was statistically lowest for pushing (with an average oxygen uptake of $17.12 \mathrm{ml} . \mathrm{kg}^{-1} . \mathrm{min}^{-}$ $\left.{ }^{1}\right)$ and highest for two-handed pulling, although there were no statistical differences between the two techniques of pulling (18.28 and $18.58 \mathrm{ml} \cdot \mathrm{kg}^{-1} \cdot \mathrm{min}^{-1}$ for 
one- and two-handed pulling respectively). More detailed analysis of the impact of technique when matched for the frequency and load moved revealed no significant differences between conditions, indicating that although overall pushing required the least oxygen, differences between comparable conditions were minimal. When matched for the load moved, only pushing and two-handed pulling at the high frequency demonstrated a difference greater than $10 \%$ between conditions.

Pushing resulted in significantly lower energy cost $\left(6.35 \mathrm{kcal} . \mathrm{min}^{-1}\right)$ than either form of pulling, there was no difference between one-handed (6.83 kcal. $\mathrm{min}^{-1}$ ) and two-handed pulling (6.97 kcal.min $\left.{ }^{-1}\right)$. These differences were greatest when comparing pushing to one- and two-handed pulling of the $500 \mathrm{~kg}$ load at a frequency of $4 \mathrm{start} / \mathrm{stops}$ per minute which were both significantly $(\mathrm{p}<0.05)$ lower than pushing.

\subsection{Impact of start/stop frequency}

The number of times the subjects were required to start and stop the trolley moving played an important role in determining the cardiovascular responses to the three techniques of pushing and pulling. There was a statistically significant $(p<0.05)$ difference between the two start/stop frequencies with the average heart rate response increasing from $108 \mathrm{bt} . \mathrm{min}^{-1}$ to 113 bt. $\mathrm{min}^{-1}$ when the number of start-stops was increased from 12 to 24 .

Increasing the start/stop frequency resulted in the oxygen consumption increasing from $17.3 \mathrm{ml} . \mathrm{kg}^{-}$ ${ }^{1} \cdot \mathrm{min}^{-1}$ for the nine $12 \mathrm{start} / \mathrm{stop}$ conditions to 18.69 $\mathrm{ml} . \mathrm{kg}^{-1} \cdot \mathrm{min}^{-1}$ for the remaining experimental conditions, an increase of approximately eight percent.

The energy cost with a frequency of 4 start/stops per minute of $6.96 \mathrm{kcal} . \mathrm{min}^{-1}$ was eight percent higher than that associated with the lower frequency of 2 start/stops per minute $\left(6.47 \mathrm{kcal} . \mathrm{min}^{-1}\right)$. Thus the frequency of start/stopping movement of the MHD would appear to contribute to the energy cost of these tasks and thus needs to be taken into consideration in the design of guidelines/recommendations for pushing and pulling.

\section{Discussion}

\subsection{Impact of load}

The load moved played a pivotal role in determining the physiological demands of the experimental conditions presented in the current study. These findings are to be expected as there is a direct relationship between the load moved and the frictional forces at the wheel/floor interface which determines the required forces. Consequently an increase in load increases the force requirements and the amount of work required from the subject. Heart rate, oxygen uptake and energy expenditure all demonstrated significant increases in responses as the load increased from 200 to $500 \mathrm{~kg}$. The findings of the current study support the argument that there is a linear relationship between the workload and oxygen uptake with a linear relationship being found between load moved and the oxygen demand for all three techniques and both frequencies. A similar linear relationship between load and energy expenditure for rickshaw pulling has been found [9]; however they did not investigate pushing or one-handed pulling. Furthermore a linear relationship between a sustained loads/forces and heart rate and oxygen uptake has been established for pushing tasks [11]. These authors found heart rate responses ranging between 120 and $139 \mathrm{bt}^{\mathrm{min}}{ }^{-1}$ (depending on the speed) for pushing with a sustained force of $98.1 \mathrm{~N}$, similar to those found for the $500 \mathrm{~kg}$ load (which had a similar sustained force) in the current study. They further investigated the difference between hauling and pushing and found the static component of muscle contraction in the upper extremities during pushing added to the energy expenditure. A study [8] using similar loads (and reported hand forces) as the current study found heart rate and oxygen consumption values similar to those reported in the current study, with heart rate peaking at $133 \mathrm{bt} . \mathrm{min}^{-1}$ for pushing of the $550 \mathrm{~kg}$ load. While it energy cost values of 28.41 and $36.84 \mathrm{~kJ} \cdot \mathrm{min}^{-1}$ for rickshaw pulling of loads from 180 to $230 \mathrm{~kg}$ have also been reported [9]. These values are significantly higher than found in the current study, with the 230 $\mathrm{kg}$ being similar to the $500 \mathrm{~kg}$ load in the current study, however comparisons here are difficult as the forces required to maneuver the rickshaw were not reported in this study [9]. This is further supported by the heart rate responses, with the average of 143 bt.min ${ }^{-1}$ higher than recorded for any of the conditions in the current study, suggesting that the forces required to be exerted by the subjects were high.

\subsection{Impact of technique}

There is substantial evidence in the literature supporting the idea that pushing and pulling are at least partly responsible for the high physical workload 
associated with manual handling tasks [8]. While early work [12] had earlier found the energetic cost of refuse collectors involved in pushing and pulling tasks to be excessive. As such an understanding of the physiological demands of pushing and pulling tasks is an important goal of ergonomics research. Contrastingly the role of technique in determining the physiological costs of the experimental conditions was significantly smaller. No differences were found between the two techniques of pulling (one and two handed), for heart rate, oxygen uptake or energy expenditure. Statistically significant differences were however evident between pushing and both forms of pulling for the basic ANOVA for all three variables. However post-hoc analysis of the individual differences between conditions revealed only limited differences (see results section for details). Pushing resulted in heart rate responses that were 2.8 and $4.6 \%$ lower than one- and two-handed pulling respectively. Similar differences between pushing and two-handed pulling in terms of heart rate responses have been recorded [8]; however these authors did not find any significant differences between the two techniques.

The differences between pushing and the two pulling techniques were more marked for the oxygen uptake and energy expenditure responses, were pushing was found to be 6.8 and $8.5 \%$ lower for oxygen uptake and 7.6 and $9.8 \%$ for energy expenditure than one- and two-handed pulling. Although [8] did not report on energy expenditure responses, they also found a significant difference between pushing and two-handed pulling, with similar percent differences (6.8-8.4\% for 400 and $550 \mathrm{~kg}$ respectively) as in the current study for oxygen consumption and heart rate. Although several other authors have investigated pushing $[9,11,13]$ and pulling [9] all of these studies were firstly conducted more than a decade ago and so may longer be valid and secondly did not compare pushing to pulling. The current study therefore is unique in comparing different techniques (pushing to pulling) but also in incorporating one-handed pulling into the study, as no studies to date have compared all three techniques to each other. It would therefore appear that the technique adopted does affect the physiological demands of pushing and pulling and that pushing would appear to be the preferable form of MHD movement from a physiological perspective.

In an early study [14] of combined static and dynamic work investigated pushing and pulling while walking on a treadmill they argued that a possible reason for the increased oxygen consumption associated with the pushing task is the reinforcement of the dynamic activity in the muscular system of the lower extremities and the trunk's postural work [14]. In a later study [11] pushing was compared to a hauling task and found pushing to be associated with greater energy cost, which they attributed to the static contractions of the musculature of the upper extremities. All three of the techniques adopted in the current study evidenced similar static contractions in the upper extremities which can partially explain the high levels of energy cost associated with some of the experimental conditions.

\subsection{Impact of start/stop frequency}

To date little research has focused on the impact of start/stop frequency on physiological demands of pushing and pulling. However biomechanical research (6) has indicated that the hand forces exerted during the initiation and stopping of movement are significantly higher than those observed during the sustained phase of movement. Correspondingly it could be assumed that the physiological demands of these periods (although they can be significantly shorter in duration) may also be higher than during the sustained phase. The findings of the current study would appear to support this argument. All three independent variables (heart rate, oxygen uptake and energy cost) demonstrated an increase when the frequency was doubled. It is therefore evident that not only the distance of the push or pull is important, but also the number of times the individual is required to initiate and stop movement. Although it should be noted that the impact of the start/stop frequency was small (less than $10 \%$ for all three variables) in comparison to the impact of the load moved.

\section{Conclusions}

The South Africa subjects in the current study exhibited significantly lower physiological demand for the pushing conditions than the other techniques suggesting that this technique is least likely to fatigue workers. These findings support previous biomechanical studies indicating that pushing is the preferable technique to be adopted.

It is apparent from this study that loads of $500 \mathrm{~kg}$ (even under ideal conditions) are likely to result in hand forces that require excessive physiological demands to be placed on the human operator. The results also indicate that increasing the frequency of start/stops has a significant impact on responses, suggesting that the high forces exerted during the initia- 
tion and stopping of movement contributes significantly to the energy cost of pushing and pulling tasks.

\section{References}

[1] P.G. Dempsey and L. Hashemi, Analysis of workers' compensation claims associated with manual materials handling,. Ergonomics (1999), 42 (1): 183 - 195

[2] J.I. Kuiper, A. Burdorf, J.H.A.M. Verbeek, M.H.W. FringsDresen, A.J. van der Beek and E.R.A. Viikare-Juntura, Epidemiologic evidence on manual materials handling as a factor for back disorders: a systematic review, International Journal of Industrial Ergonomics (1999), 24: 389 - 404

[3] W.S. Marras, Occupational low back disorder causation and control. Ergonomics (2000), 43, 880-902.

[4] M.L. Resnick and D.B. Chaffin, An ergonomics evaulation of handle height and load in maximal and submaximal cart pushing, Applied Ergonomics (1995), 26, 173-178.

[5] B. Schibye, H. Sogaard, B. Laursen, and G. Sjogaard Mechanical load on the spine during pushing and pulling, Proceedings of the 13th Triennial Congress of the International Ergonomics Assocaition, (1997), Tampere, Finland, 4, 536-538.

[6] M.J.M Hoozemans, A.J. van der Beek, M.H.W. Frings-Dresen, F.J.H. van Dijk and L.H.V. van der Woude, Pushing and pulling in relation to musculoskeletal disorders: a review of risk factors, Ergonomics (1998), 41, 757-781.
[7] K.W. Al-Eisawi C.J. Kerk, J.J. Congleton, A.A. Amendola, O.C. Jenkins and W.G. Gaines, Factors affecting minimum push and pull forces of manual carts, Applied Ergonomics (1999), 30, 235-245.

[8] A.J. Van der Beek, M.J.M Hoozemans, M.H.W. FringsDresen and A. Burdorf, Assessment of exposure to pushing and pulling in epidemiological field studies: an overview of methods, exposure measures, and measurement strategies, International Journal of Industrial Ergonomics (1999), 24, 417-429.

[9] S.R. Datta, B.B. Chatterjee and B.N. Roy, The energy cost of rickshaw pulling, Ergonomics (1978), 21 (11): 879 - 886.

[10] J.E. Viljoen and C.J. Christie, Excellent work-place quality: questionable socio-economics. In Goebel et al. (editors). Proceedings Human Factors in Organizational Design and Management X(2011), 2: 133 - 138.

[11] M. Garcin, J.Y. Cravic, H. Vandewalle and H. Monod, Physiological strains while pushing or hauling, European Journal of Applied Physiology (1996), 71: 478 - 482.

[12] M.H.W. Frings-Dresen, H.G.C. Kemper, .R.A. Stassen, I.F.A.M. Crolla and A.M.T. Markslag, The daily work load of refuse collectors working with three different collecting methods: a field study, Ergonomics (1995), 38 (10): 2045 2055.

[13] M.F. Haisman and R.F. Goldman, Effect of terrain on the energy cost of walking with back loads and handcart loads, Journal of Applied Physiology (1977), 36 (5): 545 - 548.

[14] J. Sanchez, H. Monod and F. Chabaud, Effects of dynamic, static and combined work on heart rate and oxygen consumption, Ergonomics (1978), 22: 935 - 943. 